\title{
Synergistically Anti-metastatic Effect of 5-Flourouracil on Colorectal Cancer Cells via Calcium-mediated Focal Adhesion Kinase Proteolysis
}

\author{
MINHEE PARK ${ }^{1}$, PASUPATHI SUNDARAMOORTHY ${ }^{1}$, JAE JUN SIM $^{1}$, \\ KEUN-YEONG JEONG ${ }^{2}$ and HWAN MOOK KIM ${ }^{1}$ \\ ${ }^{1}$ Gachon Institute of Pharmaceutical Science, Gachon University, Incheon, Republic of Korea; \\ ${ }^{2}$ Oncometplus Pharmaceuticals Co., R\&D division, Incheon, Republic of Korea
}

\begin{abstract}
Aim: To investigate the possibility of enhancing an anti-metastatic effect of 5-fluorouracil (5-FU) on colorectal cancer (CRC) cells by combining it with continuous calcium supplementation. Materials and Methods: Optimal doses of 5-FU with/without lactate salt (CaLa) were determined via clonogenicity and 3-(4,5-dimethylthiazol-2-yl)-2,5-diphenyltetrazolium bromide assays using human CRC cells cultured on normal or low-attachment plates. Invasion and migration assays confirmed the enhanced anti-metastatic effect of combining 5-FU and CaLa. Western blot analysis for elements of the focal adhesion kinase (FAK) signaling cascade and epithelial-mesenchymal transition (EMT) markers was used to investigate the underlying mechanism. Results: 5-FU $(2.5 \mu M)$ had no antitumor activity against unanchored CRC cells, while it significantly suppressed anchorage-dependent cell proliferation. In contrast, treatment with CaLa (2.5 mM), alone and in combination with 5-FU, exerted antitumor activity against both anchored and unanchored CRC cells via calcium-mediated FAK proteolysis and inhibition of EMT markers, such as vimentin and SNAIL. Conclusion: Calcium supplementation represents a method of enhancing the potency of existing antitumor agents such as 5-FU, augmenting their clinical effectiveness.
\end{abstract}

This article is freely accessible online.

Correspondence to: Hwan Mook Kim, Ph.D., Gachon Institute of Pharmaceutical Sciences, Gachon University, Incheon 406-840, Republic of Korea. Tel: +82 328996446, Fax: +82 328204829, email: hwanmook@gachon.ac.kr and Keun-Yeong Jeong, Ph.D., Oncometplus Pharmaceuticals Co., R\&D Division, Yeonsu-Gu, Incheon 22006, Republic of Korea. Tel: +82 322050541, Fax: +82 322050542, e-mail: alvirus@naver.com

Key Words: Colorectal cancer, metastasis, 5-FU, lactate calcium salt, focal adhesion kinase, epithelial-mesenchymal transition, combination treatment.
Colorectal cancer (CRC) is the third most commonly diagnosed cancer and the third leading cause of cancerrelated death in both men and women (1). According to the estimates of the Global Cancer Control (GLOBOCAN) project, nearly 1.4 million people worldwide were diagnosed with CRC in 2012, with the Republic of Korea displaying the highest incidence rates, followed by Slovakia and Hungary (2).

CRC that has grown into the wall can penetrate blood or lymph vessels; typically, cancer cells first invade nearby lymph nodes, and then spread to other parts of the body, such as the liver or lung $(1,3)$. Approximately 150,000 new cases are diagnosed each year, with about $20 \%$ of them already displaying metastases (2). Metastatic CRC is often harder to treat and tends to have a poor treatment outcome. As a result, patients with metastatic CRC have a low 5-year survival rate of about $11 \%(1,2)$.

In patients newly diagnosed with CRC, 5-fluorouracil (5FU) is usually administered intravenously in combination with a second drug called leucovorin (4). Moreover, most patients with newly-diagnosed metastatic CRC undergo surgery after receiving chemotherapy with 5-FU (5). Other combinatorial treatments have also been tested for first-line chemotherapy of metastatic CRC, where a targeted drug, such as bevacizumab or cetuximab, is co-administered to increase the efficiency of 5-FU (6). However, these regimens suffer from increased toxicity, and cause symptoms such as neutropenia, severe diarrhea, and vomiting (7). Moreover, 5FU is not an effective treatment strategy because it only delays micrometastasis. The mechanism through which 5-FU acts on CRC metastases remains unclear (8).

Focal adhesion kinase (FAK), a protein kinase involved in cellular adhesion, is activated in several types of advancedstage cancer. In CRC cells, phosphorylation of FAK occurs on multiple residues, and overexpression of FAK has been detected in liver metastases of CRC (9). FAK has been implicated in the regulation of the expression of genes 
associated with epithelial-mesenchymal transition (EMT) (10). FAK inhibitors have been shown to reduce tumor metastasis and possess initial clinical activity in patients while having limited adverse effects (11).

Calpains are proteins belonging to the family of calciumdependent proteolytic enzymes. They are expressed in almost all eukaryotes and some bacteria, but not in archaeobacteria (12). Calpains can destroy constituents of focal contacts such as FAK, i.e. FAK is subject to calpain-mediated proteolysis $(11,13)$. Due to the role of FAK in EMT, calpain-dependent proteolysis of FAK may have the potential to suppress cancer cell motility (13).

Calcium lactate $(\mathrm{CaLa})$ is a crystalline salt formed by the reaction between lactic acid and calcium carbonate. CaLa is most commonly used for calcium supplementation in medicine to treat calcium deficiencies such as hypocalcaemia syndromes (14). The neutral chemical structure of CaLa gives it the remarkable property of being able to easily diffuse into cells without the need for a specific ion channel. It has been reported that $\mathrm{CaLa}$ treatment leads to a significant uptake of calcium by CRC cells (15).

In the present study, we used CRC cells to investigate the possibility of enhancing the intrinsic mechanism of 5-FU action, thus reducing the required dose of the agent, by longterm calcium supplementation. We focused on the ability of calcium to mediate FAK proteolysis, resulting in lower expression of EMT markers.

\section{Materials and Methods}

Cell culture and reagents. Human CRC cell lines (HCT-116 and HT-29) were purchased from the American Type Culture Collection (Manassas, VA, USA). Cells were maintained in RPMI-1640 medium (Welgene, Daegu, South Korea) supplemented with $10 \%$ fetal bovine serum (Welgene), $100 \mathrm{IU} / \mathrm{ml}$ penicillin, and $100 \mu \mathrm{g} / \mathrm{ml}$ streptomycin (Welgene) in a humidified atmosphere of $5 \% \mathrm{CO}_{2}$, at $37^{\circ} \mathrm{C}$. 5-FU, CaLa, calpeptin (calpain inhibitor), and Z-Leu-Leu-Leu-al (MG132; proteasome inhibitor) were purchased from Sigma-Aldrich (St. Louis, MO, USA). Primary and secondary anti-rabbit antibodies for western blot analysis were purchased from Cell Signaling Technology (Danvers, MA, USA). The primary antibodies recognized the following proteins: FAK, SRC proto-oncogene, non-receptor tyrosine kinase (SRC), AKT serine/threonine kinase 1 (AKT), nuclear factor kappa B (NF-kB), snail family transcriptional repressor 1 (SNAI1), vimentin, lamin B, and glyceraldehyde 3phosphate dehydrogenase (GAPDH).

Colony formation assay. HCT-116 and HT-29 cells were seeded at a density of $2.5 \times 10^{2}$ cells/well in a normal 6-well plate. After $24 \mathrm{~h}$, cells were treated with different concentrations of CaLa $(0.5,1$, and $2.5 \mathrm{mM}), 5-\mathrm{FU}(1,2.5$, and $5 \mu \mathrm{M})$, or a combination of the two. After 14 days, the colonies were fixed with methanol and stained using hematoxylin (Thermo Fisher Scientific, Waltham, MA, USA). The number of grown colony was counted under an optical microscope (Olympus, Center Valley, PA, USA).
Anoikis analysis. HCT-116 and HT-29 cells were seeded at a density of $1.0 \times 10^{6}$ cells/well in Ultra-Low attachment 24-well plates (Costar, Corning, NY, USA). After $24 \mathrm{~h}$, cells were treated with different concentrations of CaLa $(0.5,1$, and $2.5 \mathrm{mM}), 5-\mathrm{FU}(1,2.5$, and $5 \mu \mathrm{M}$ ), or a combination of the two, for another $12 \mathrm{~h}$ and $24 \mathrm{~h}$. Cells were harvested, and a volume of cell suspension was mixed with an equal volume of a $0.4 \%$ Trypan blue solution (Thermo Fisher Scientific). The number of stained cell was counted using a hemocytometer (Marienfeld, Lauda-Königshofen, Germany).

Re-attachment assay. HCT-116 and HT-29 cells were seeded at a density of $1.0 \times 10^{6}$ cells/well in Ultra-Low attachment 24 -well plates (Costar) and treated with different concentrations of CaLa $(0.5,1$, and $2.5 \mathrm{mM}), 5-\mathrm{FU}(1,2.5$, and $5 \mu \mathrm{M})$, or a combination of the two, for $24 \mathrm{~h}$. The cells were harvested and re-seeded in normal 6-well plates. The rate of cell death was determined using a Cell Counting Kit-8 (Enzo Life Sciences, Farmingdale, NY, USA). A volume $(10 \mu \mathrm{l})$ of the Cell Counting Kit- 8 solution was added to each well. After a 1-h incubation, the absorbance was measured using an Epoch Micro-Volume Spectrophotometer (Bio Tek, Winooski, VT, USA) at an absorbance wavelength of $450 \mathrm{~nm}$.

Fluorescence-activated cell sorting (FACS) analysis. HCT-116 and HT-29 cells were seeded at a density of $1.0 \times 10^{6}$ cells/well in UltraLow attachment 24-well plates (Costar) and treated with different concentrations of $\mathrm{CaLa}, 5-\mathrm{FU}$, or a combination of the two. The cells were incubated at $37^{\circ} \mathrm{C}$ in a $5 \% \mathrm{CO}_{2} / 95 \%$ air atmosphere for 12 hours. After treatment, cells were washed with cold phosphatebuffered saline (PBS) and resuspended in binding buffer (BD Biosciences, Great Lakes, NJ, USA) at a density of $1.0 \times 10^{6}$ cells $/ \mathrm{ml}$. A volume $(5 \mu \mathrm{l})$ of a fluorochrome-conjugated annexin $\mathrm{V}$ solution was added to $100 \mu \mathrm{l}$ of the cell suspension and gently mixed. Cells were then incubated in the dark for $15 \mathrm{~min}$ at room temperature, washed with $2 \mathrm{ml}$ binding buffer, and resuspended in $200 \mu \mathrm{l}$ of binding buffer. Finally, $5 \mu \mathrm{l}$ of propidium iodide solution was added. Annexin V/propidium iodide were measured using a BD FACSCalibur flow cytometer (BD Biosciences). Apoptotic rates were evaluated using the BD FACSComp software (BD Biosciences).

Protein extraction. HCT-116 and HT-29 cells were seeded at a density of $1.0 \times 10^{6}$ cells/well in Ultra-Low attachment 24-well plates (Costar) and treated with different concentrations of $\mathrm{CaLa}(0.5,1$, and $2.5 \mathrm{mM}), 5-\mathrm{FU}(1,2.5$, and $5 \mu \mathrm{M})$, or a combination of the two, for $12 \mathrm{~h}$ and $24 \mathrm{~h}$. Cells were harvested and washed once with ice-cold PBS. To extract the total cell lysate, washed cells were lysed by RIPA lysis buffer (Roche, Basel, Switzerland) and centrifuged at 10,000 $\times g$ for $10 \mathrm{~min}$ at $4^{\circ} \mathrm{C}$. The supernatant was used for protein analysis. To extract the nuclear fraction, washed cells were resuspended in $100 \mu \mathrm{l}$ of a lysis buffer containing $20 \mathrm{mM}$ Tris- $\mathrm{HCl}$ ( $\mathrm{pH}$ 7.6), $1 \mathrm{mM}$ EDTA, $140 \mathrm{mM} \mathrm{NaCl}, 1 \% \mathrm{NP}-40,1 \%$ aprotinin, $1 \mathrm{mM}$ phenylmethylsulfonyl fluoride, and $1 \mathrm{mM}$ sodium vanadate. After a 30-min incubation on ice, the lysates were centrifuged at $12,000 \times g$ for $20 \mathrm{~min}$ at $4^{\circ} \mathrm{C}$. The pellet was washed with ice-cold PBS and resuspended in cell extraction buffer (Thermo Fisher Scientific).

Western blot analysis. Whole-cell or nuclear lysates were transferred onto polyvinylidene fluoride membranes (Merck Millipore, Billerica, MA, USA). After blocking in 5\% non-fat milk (Bio-Rad, Hercules, CA, USA) for $1 \mathrm{~h}$, membranes were incubated overnight 
at $4{ }^{\circ} \mathrm{C}$ with primary antibody diluted in tris-buffered saline and Tween 20 (TBST) containing $100 \mathrm{mM}$ Tris- $\mathrm{HCl}(\mathrm{pH} 7.5), 1.5 \mathrm{M}$ $\mathrm{NaCl}$, and $0.5 \%$ Tween-20 obtained from Sigma-Aldrich, to which $5 \%$ bovine serum albumin (BSA) and $0.1 \%$ sodium azide (SigmaAldrich) had been added. The specific dilutions for each antibody were as follows: FAK: 1:1,000; p-FAK: 1:1,000; SRC: 1:1,000; p-SRC: 1:1,000; AKT: 1:1,000; NF-кB: 1:1,000; vimentin: 1:1,000; SNAI1: 1:1,000; lamin B: 1:1,000; and GAPDH: 1:5,000. On the next day, membranes were washed with TBST and incubated for $2 \mathrm{~h}$ with anti-rabbit secondary antibody $(1: 5,000)$. Immunoblots were developed using a western blot detection reagent (Abclone, Seoul, Korea) and exposed to x-ray film (Agfa, Leverkusen, Germany) to perform qualitative assay.

Trans-well invasion assay. The assay was performed using a $6.5 \mathrm{~mm}$ trans-well insert with an $8.0-\mu \mathrm{m}$ pore-size polycarbonate membrane filter (Costar). The insert was placed in 24-well plates, with each well containing $1 \mathrm{ml}$ serum-free RPMI-1640 medium. HCT-116 and HT-29 cells were seeded at a density of $3.5 \times 10^{5}$ cells/insert onto the upper side of the inserts. Then, the cells were treated with $2.5 \mu \mathrm{M}$ 5-FU, $2.5 \mathrm{mM} \mathrm{CaLa}$, or a combination of two and incubated at $37^{\circ} \mathrm{C}$ for $18 \mathrm{~h}$. After incubation, the insert was carefully washed with sterile water, and then transferred to $100 \%$ methanol to fix the cells. After fixation, the membrane filter was stained with hematoxylin and eosin. Images depicting cell invasion were taken under an optical microscope (Olympus) equipped with a digital camera (Nikon, Tokyo, Japan).

Wound-healing assay. Two chambers separated by a $500 \mu \mathrm{m}$-thick wall were used for wound-healing assays (Ibidi, München, Germany). HCT-116 or HT- 29 cells $\left(100 \mu\right.$ l containing $5 \times 10^{5}$ cells $)$ were seeded into each of the two chambers and incubated for $24 \mathrm{~h}$. After incubation, the wall was gently removed creating a $\sim 500 \mu \mathrm{m}$ long area without cells. After replacing the medium with a fresh one containing CaLa, 5-FU, or a combination of the two, the cells were allowed to migrate into the bare area for $6 \mathrm{~h}$. Consecutive images of migrating cells were taken by a JuLi Br Live cell analyzer (NanoEnTek, Seoul, South Korea).

Statistical analysis. Data are presented as means \pm standard deviation (SD). Statistical significance was analyzed using the Student's $t$-test or one-way ANOVA, depending on the normality of the data distribution. A value of $p<0.05$ was deemed statistically significant. All statistical analyses were performed using Sigma Stat v3.5 (Systat Software, San Jose, CA, USA).

\section{Results}

5-FU inhibits anchorage-dependent CRC cell proliferation. To measure the clonogenicity of CRC cells, colonies of HCT-116 or HT-29 cells were counted after treatment with different doses of 5-FU. Representative images of cultures are displayed in Figure 1A and C. Images of single colonies were magnified to study the morphological features (Figure $1 \mathrm{~A}$ and $\mathrm{C}$ ). The results demonstrated that at a $5-\mathrm{FU}$ concentration of $2.5 \mu \mathrm{M}$, colonies of both HTC-116 and HT29 cells were smaller compared to those grown at lower concentrations or in the absence of 5-FU. At $5 \mu \mathrm{M} 5$-FU, HTC-116 colonies exhibited an even smaller size, while no colonies of HT-29 formed (Figure 1A and C). As seen in Figure $1 \mathrm{~B}$ and $\mathrm{D}$, the number of colonies of both cell lines was also significantly reduced in a dose-dependent manner and as mentioned, no colonies were formed by HT-29 cells when treated with $5 \mu \mathrm{M}$ 5-FU.

5-FU does not induce anchorage-independent death of CRC cells. We assessed the effects of different doses of 5-FU on the viability of CRC cells cultured on low-attachment plates (Figure 2). A significant change in viability was only observed after $24 \mathrm{~h}$ treatment with $5 \mu \mathrm{M} 5$-FU. Under this condition, the cell viability of HCT-116 and HT-29 cells relative to controls decreased (Figure $2 \mathrm{~A}$ and D). 5-FUtreated CRC cells were still alive at the time of re-seeding on a normal culture plate. As seen in Figure $2 \mathrm{~B}$ and $\mathrm{E}$, a significant $(p<0.05)$ increase in death rate was only observed in HT-29 cells treated with $5 \mu \mathrm{M} 5$-FU, which displayed a death rate $5.72 \%$ higher than the rate of the control group. Nonetheless, no group (including the $5 \mu \mathrm{M}$ 5-FU-treated HT29 cells) displayed significant differences in the late apoptosis analysis (Figure 2C and F).

Calcium supplement inhibits anchorage-dependent CRC cell proliferation. Figure $3 \mathrm{~A}$ and $\mathrm{C}$ display representative images of HCT-116 and HT-29 colonies following treatment with different CaLa concentrations. These images suggest that $\mathrm{CaLa}$ causes a dose-dependent reduction in colony number. In HCT116 cells, a significant decrease in the number of colonies was only observed in cultures treated with $2.5 \mathrm{mM} \mathrm{CaLa}(p<0.05)$. In the case of HT-29 cells, the number of colonies was significantly decreased with $0.5 \mathrm{mM} \mathrm{CaLa}$, and $1 \mathrm{mM} \mathrm{CaLa}$ $(p<0.001)$. HT-29 colonies of any form were not observed in the 2.5-mM CaLa-treated group (Figure 3C and D).

Calcium supplementation induces anchorage-independent CRC cell death. Calcium supplementation via CaLa tended to inhibit anoikis evasion of CRC cells grown in lowattachment plates (Figure 4). While 12-h treatment with 0.5 $\mathrm{mM}$ CaLa had no significant effect, 24-h treatment reduced the viability of HCT-116 and HT-29 cells $(p<0.05$ and $p<0.001$ ), respectively. Treatment with $1 \mathrm{mM}$ and $2.5 \mathrm{mM}$ CaLa reduced the viability of HCT-116 and HT-29 cells at both 12-h and 24-h (Figure 4A and D). Treatment with CaLa also increased the CRC cell death when re-seeded on normal culture plates.

Changes in death rates are displayed in Figure 4B and E. In HCT-116 cells, treatment with 1.0 and $2.5 \mathrm{mM} \mathrm{CaLa}$ significantly increased the death rate relative to controls $(p<0.001)$. In the case of HT29 cells, the death rate significantly increased after treatment with 1 and $2.5 \mathrm{mM}$ CaLa. As seen in Figure 4C and F, treatment of cells with $2.5 \mathrm{mM}$ CaLa also augmented late apoptosis HCT-116 and HT-29 cells $(p<0.001)$. 
A

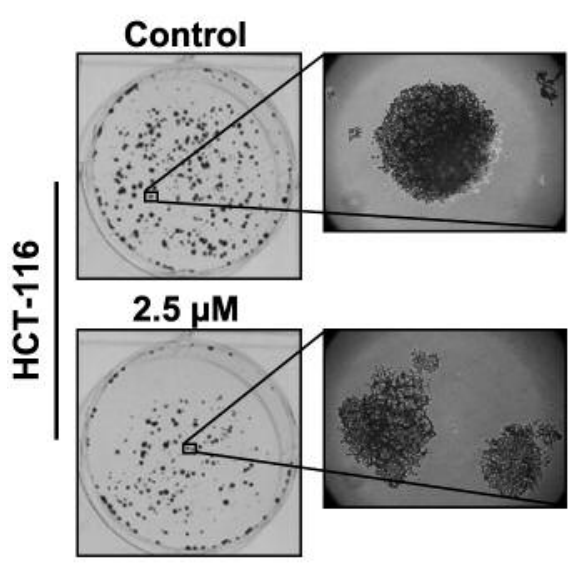

C

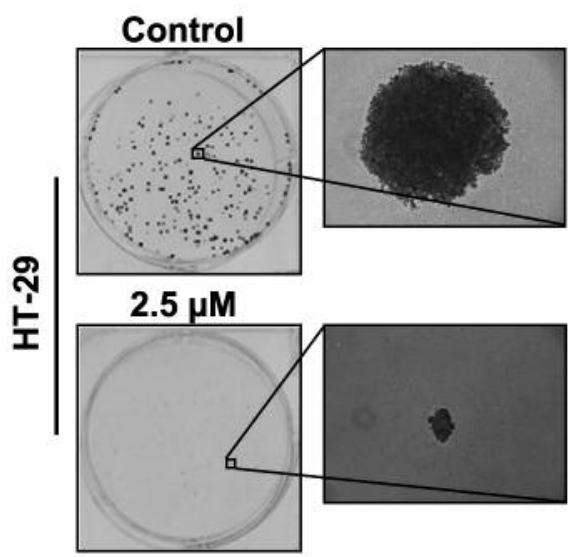

$1.0 \mu \mathrm{M}$

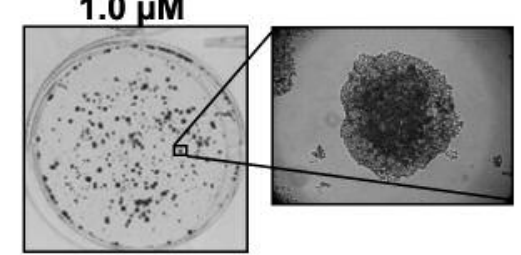

$5.0 \mu \mathrm{M}$
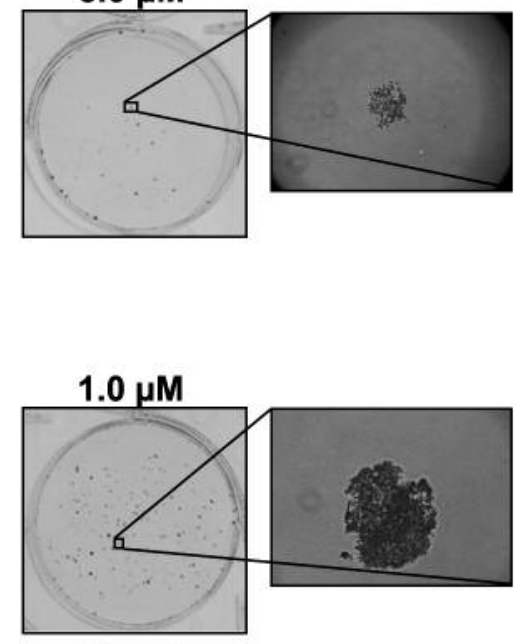

$5.0 \mu \mathrm{M}$

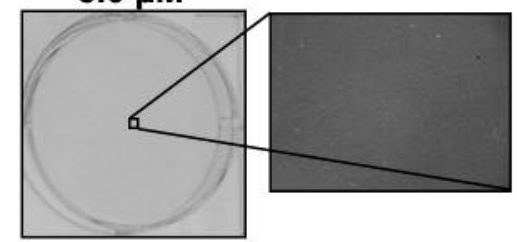

D

B
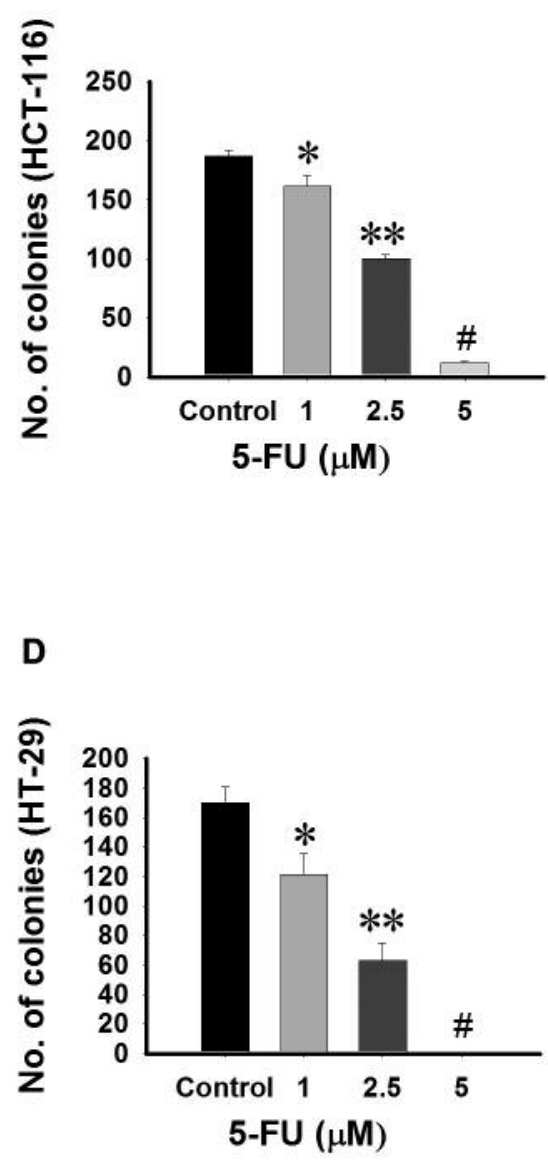

Figure 1. Measurement of clonogenicity using colorectal cancer (CRC) cells cultured on normal plates to confirm the inhibition of anchoragedependent cell proliferation by 5-fluorouracil (5-FU). Representative images $(A, C)$ and quantitative analysis $(B, D)$ of HoCT-116 (A, B) and HT$29(C, D)$ colonies after treatment with different doses of 5-FU. All experiments were carried out in five replications per group. Results are means $\pm S D ; * p<0.05$ and $* * p<0.001$ vs. Control; \#p<0.001 vs. Control, $1.0 \mu M$ and $2.5 \mu M$ groups.

Calcium-mediated FAK degradation inhibits the expression of EMT markers. To determine the mechanism underlying the antitumor effect of sustained calcium supplementation, FAK signaling cascade and EMT nuclear markers were examined by western blot analysis. The results showed no statistically significant differences in the expression of FAK signaling molecules nor of EMT markers between the control and the 5-FU-treated groups, even though 5-FU treatment did cause a slight increase in FAK and NF- $\mathrm{kB}$ expression (Figure 5A and B). In contrast, CaLa treatment clearly reduced the levels of FAK signaling molecules, including SRC and AKT. Moreover, CaLa dose-dependently reduced the levels of EMT markers that are dependent on FAK signaling (Figure 5C and D). Lamin B was used as a loading control for the nuclear fraction (Figure 5B and D).
In order to examine whether the effects of CaLa were a result of calpain-mediated proteasomal degradation of FAK, CaLa was administered alone or together with calpeptin. The presence of either inhibitor led to recovery of FAK levels (Figure 5E and F).

Combination of 5-FU and CaLa induces CRC cell death irrespective of anchorage state. Representative images of colonies after the clonogenicity assay are shown in Figure 6A and C. In both HCT-116 and HT-29 cells, co-treatment with $2.5 \mathrm{mM} \mathrm{CaLa}$ and $5 \mu \mathrm{M} 5$-FU resulted in smaller colonies. Co-treatment also had a greater effect on the number of colonies (Figure 6B and D) than did single treatments. Cell viability was assessed in cells grown in low-attachment plates and treated with 5-FU, CaLa, or a combination of the two 

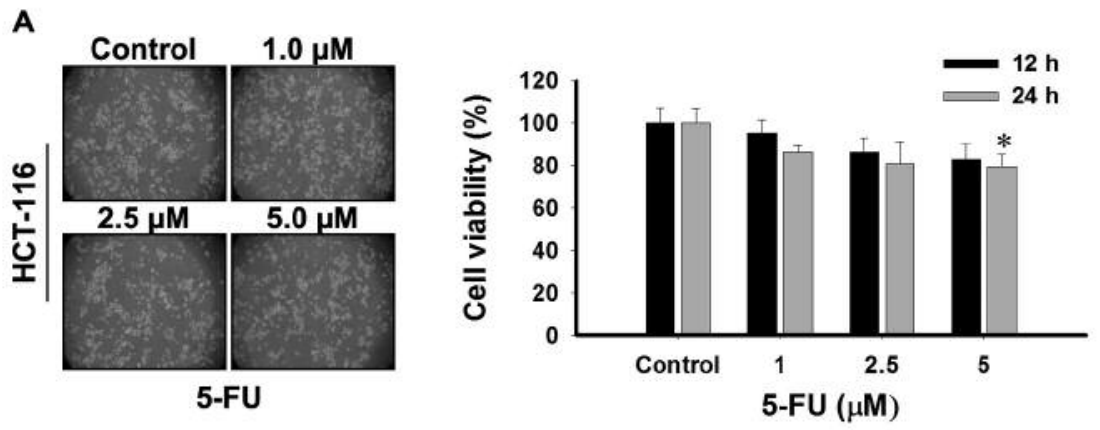

B

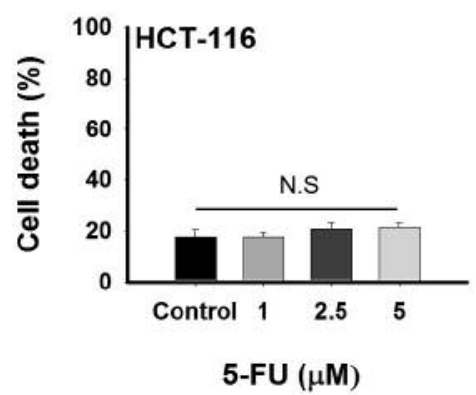

C

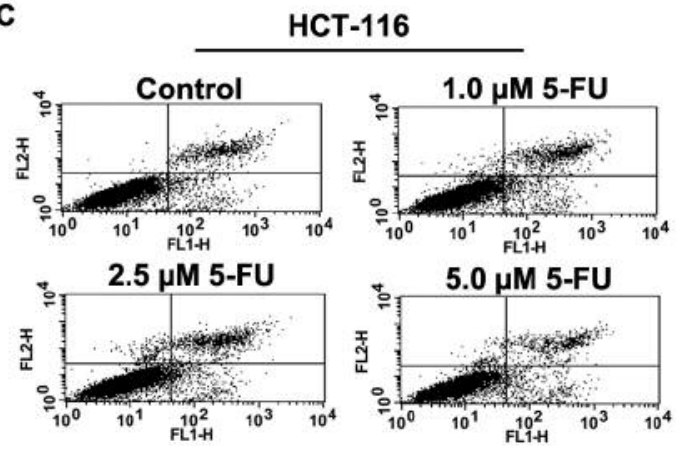

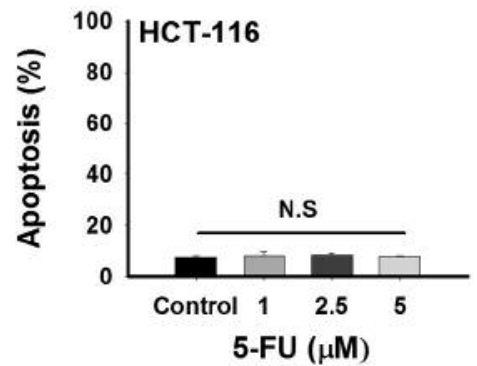
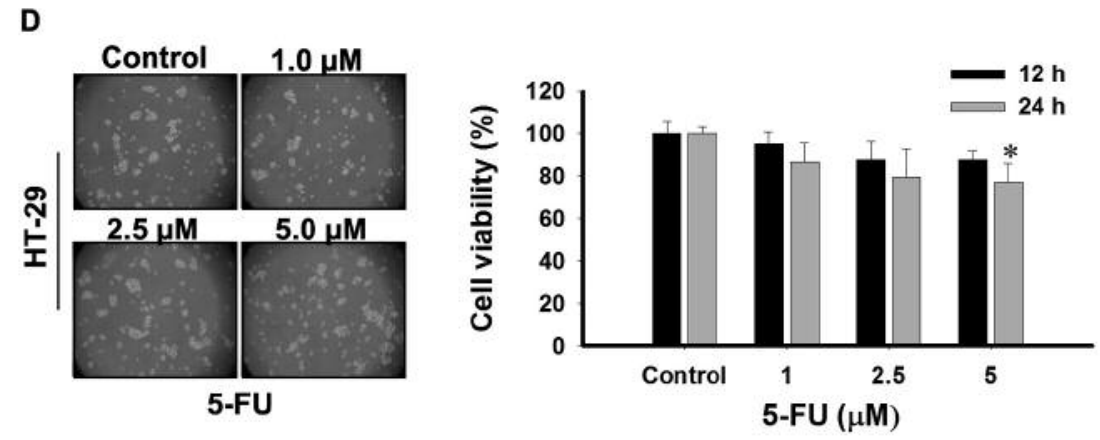

E

$\mathbf{F}$

HT-29
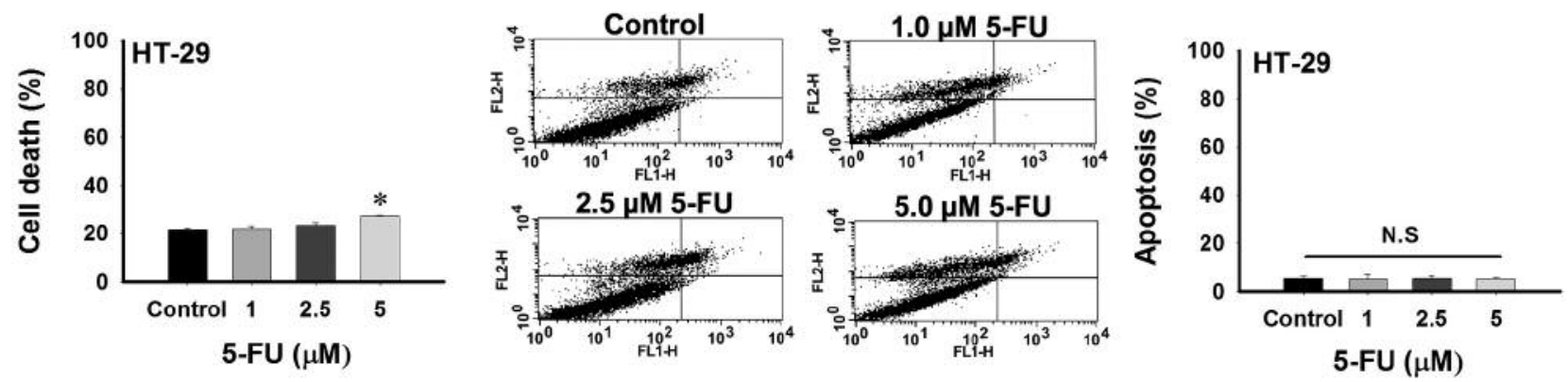

Figure 2. Measurement of anoikis using colorectal cancer (CRC) cells cultured on low-attachment plates to confirm the effect of 5-fluorouracil (5-FU) on anchorage-independent cell death. Trypan blue exclusion assay for HCT-116 (A) and HT-29 cell (D) cell counting after treatment with different doses of 5-FU. Rates of cell death after re-seeding the unanchored HCT-116 (B) and HT-29 (E) cells on normal plates. Quantitative analysis of late apoptosis via fluorescence-activated cell sorting after annexin V staining of HCT-116 (C) and HT-29 (F) cells. All experiments were carried out in five replications per group. Results are means $\pm S D$. ${ }^{*} p<0.05$ vs. Control. N.S: Not significant difference between groups. 
A

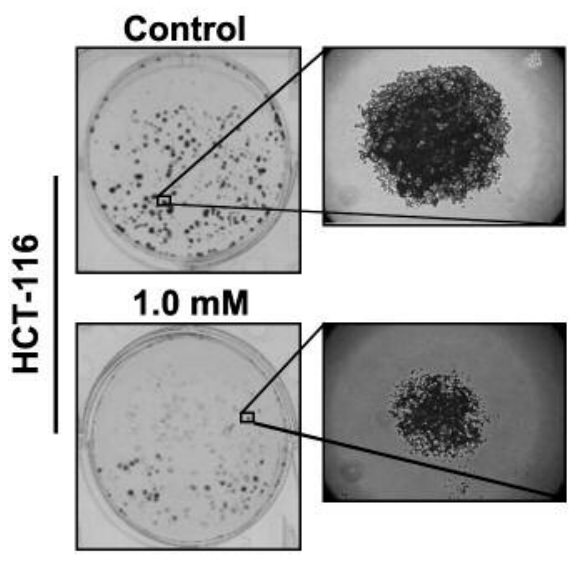

C

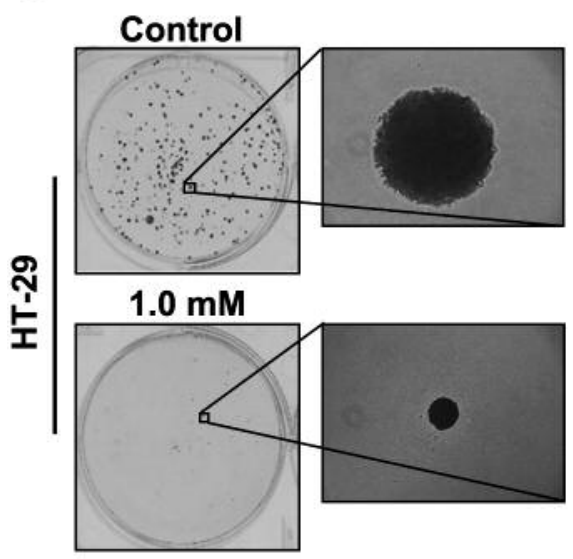

$0.5 \mathrm{mM}$

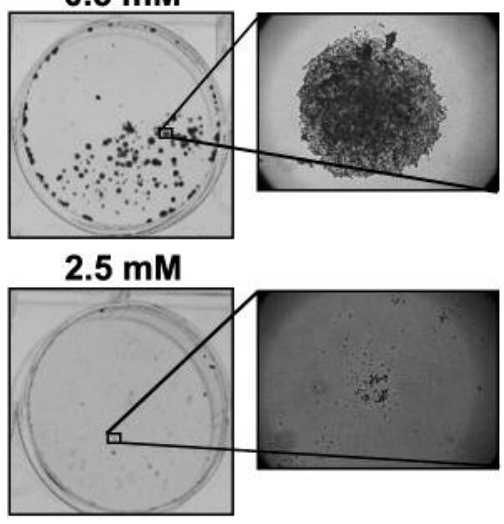

$0.5 \mathrm{mM}$

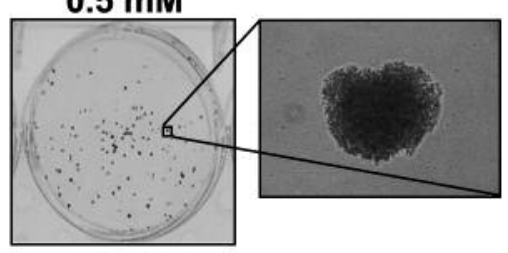

$2.5 \mathrm{mM}$

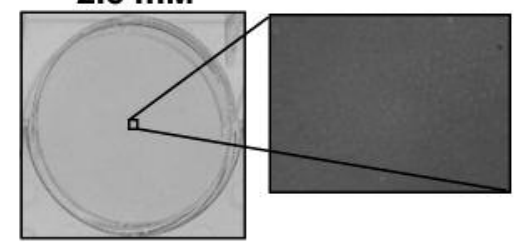

B

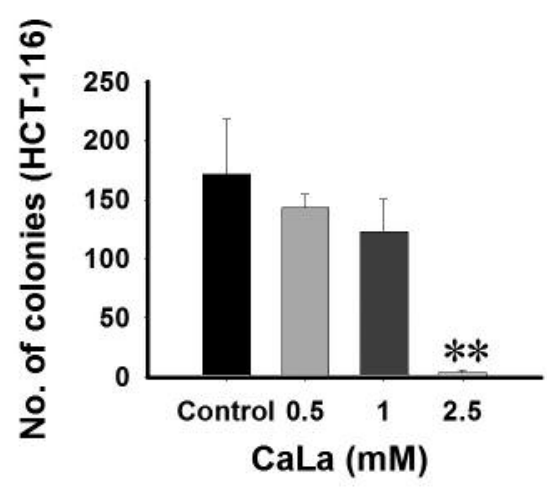

D

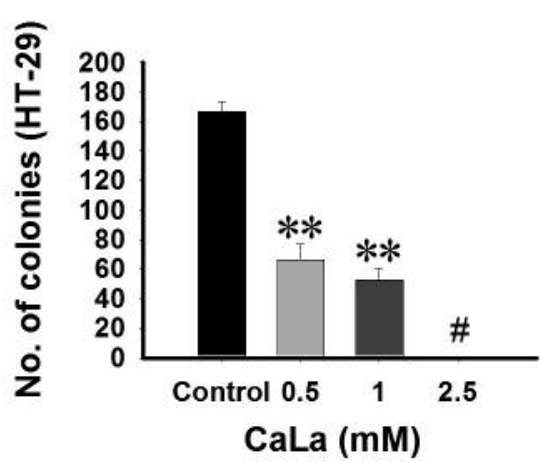

Figure 3. Measurement of the clonogenicity of colorectal cancer (CRC) cells grown on normal plates to confirm the inhibitory effect of calcium supplementation on anchorage-dependent cell proliferation. Representative images $(A, C)$ and quantitative analysis $(B, D)$ of $H C T-116(A, B)$ and $H T-29(C, D)$ colonies after treatment with different doses of lactate calcium salt $(C a L a)$. All experiments were carried out in five replications per group. Results are means $\pm S D ; * * p<0.001 \mathrm{vs.} \mathrm{Control;}{ }^{*} p<0.001 \mathrm{vs}$. Control, $1.0 \mathrm{mM}$ and $2.5 \mathrm{mM}$ groups.

(Figures 6E-H and 7A-D). As seen in Figure 6E and G, the combined treatment had a clearly more severe effect on cell viability compared to treatment with only one of the two chemicals $(p<0.001)$ (Figure $6 \mathrm{~F}$ and $\mathrm{H})$. Evaluation of cell death after re-seeding on normal culture plates showed that the cell death ratios of HCT-116 and HT-29 cells after cotreatment were also significantly higher $(p<0.001)$ than the rates of the controls and single treatments (Figure 7A and $C$ ). Late apoptosis was also enhanced by co-treatment as shown in Figure 7B and D $(p<0.001)$ compared to controls, cells treated with $2.5 \mathrm{mM} \mathrm{CaLa} \mathrm{(about} 20 \%$ lower than the rates of the co-treated cells in both cell types), and cells treated with $2.5 \mu \mathrm{M}$ 5-FU (rates similar to controls in both cell types). Moreover, western blot analysis demonstrated that cotreatment caused a clear decrease in the levels of FAK signaling molecules, including SRC and AKT (Figure 7E), while there was also a significant decrease in the expression of NF-kB, SNAI1, and vimentin, which are well known markers of cancer invasion and metastasis (Figure $7 \mathrm{E}$ and $\mathrm{F}$ ).

The combination of 5-FU and CaLa exerts an enhanced antimetastatic effect on CRC cells. In order to confirm the enhanced anti-metastatic effect of the co-treatment, we assessed the invasiveness and motility of HCT-116 and HT29 cells (Figure 8). The representative images shown in Figure $8 \mathrm{~A}$ and $\mathrm{C}$ demonstrate a clear decrease in invasiveness after treatment with $2.5 \mathrm{mM} \mathrm{CaLa}$ or with the combination of $2.5 \mathrm{mM}$ CaLa and $2.5 \mu \mathrm{M} 5$-FU. After $18 \mathrm{~h}$ of combination treatment, the invasion rate significantly decreased by half or more $(p<0.001)$. Treatment with $2.5 \mu \mathrm{M}$ 

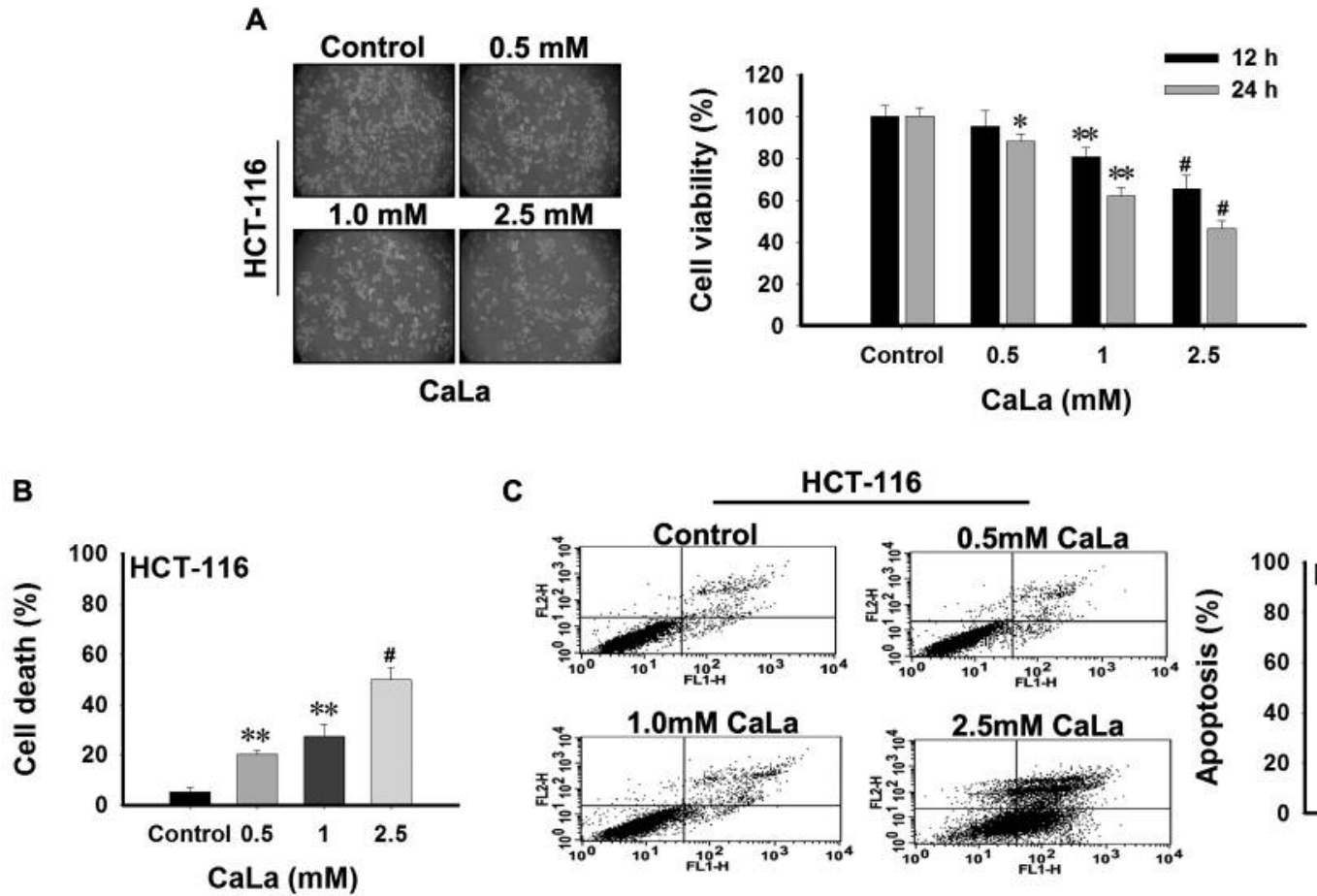

HCT-116
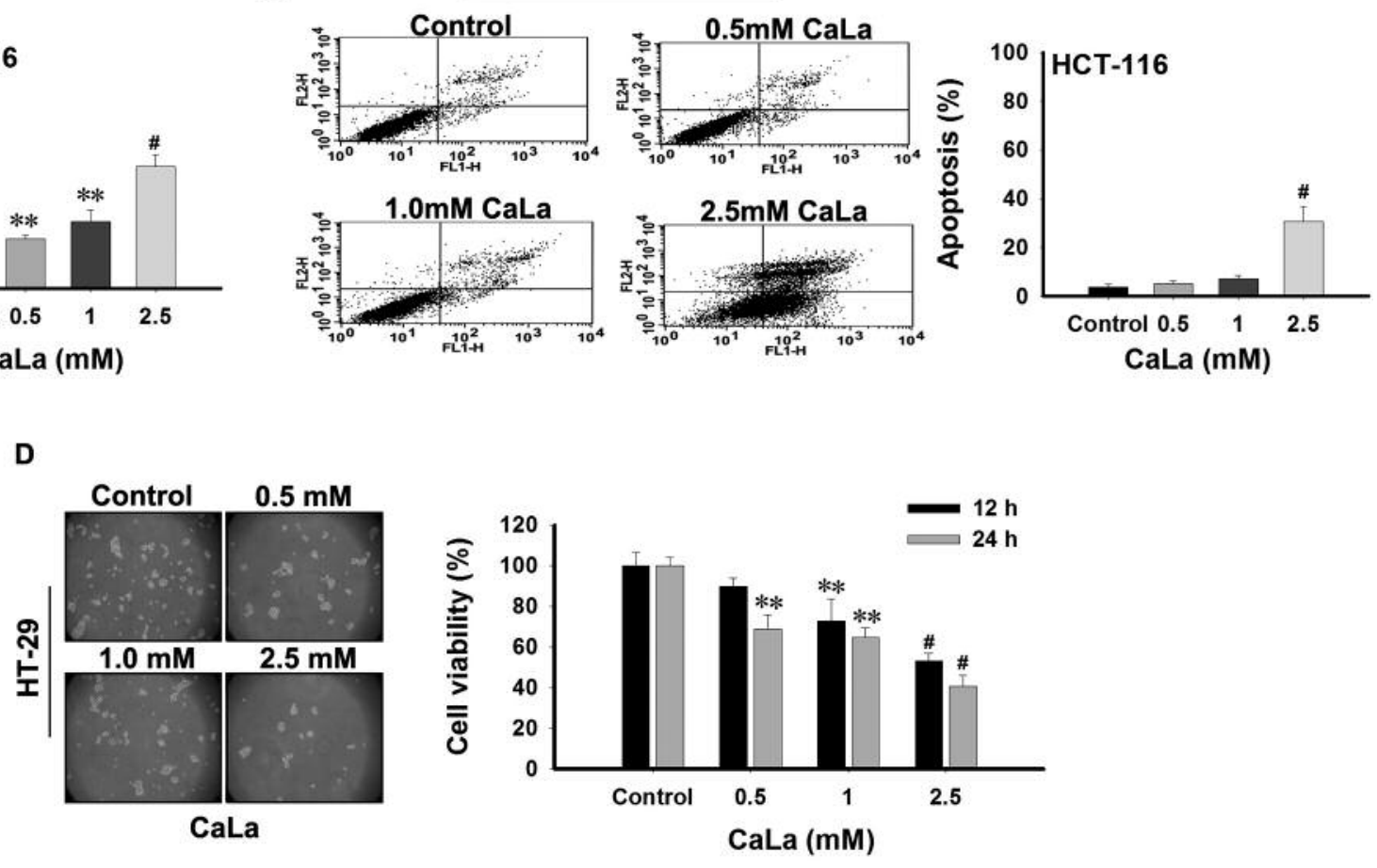

E

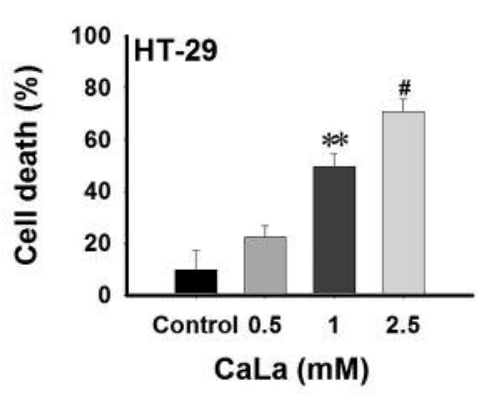

$\mathbf{F}$

Figure 4. Measurement of anoikis using colorectal cancer (CRC) cells cultured on low-attachment plates to confirm the association of anchorageindependent cell death with calcium supplementation. Trypan blue exclusion assay for HCT-116 (A) and HT-29 (D) cell counting after treatment with different doses of lactate calcium salt (CaLa). Rates of cell death after re-seeding the unanchored HCT-116 (B) and HT-29 (E) cells on normal plates. Quantitative analysis of late apoptosis via fluorescence-activated cell sorting after annexin V staining of HCT-116 (C) and HT-29 (F) cells. All experiments were carried out in five replications per group. Results are means $\pm S D ; * p<0.05$ and $* * p<0.001 \mathrm{vs}$. Control; ${ }^{*} p<0.001 \mathrm{vs}$. Control, $1.0 \mathrm{mM}$ and $2.5 \mathrm{mM}$ groups. 
A

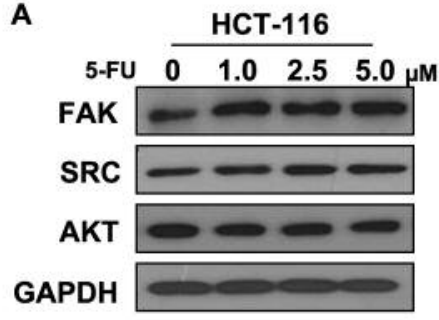

B

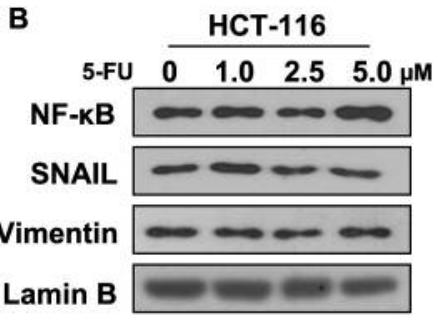

C

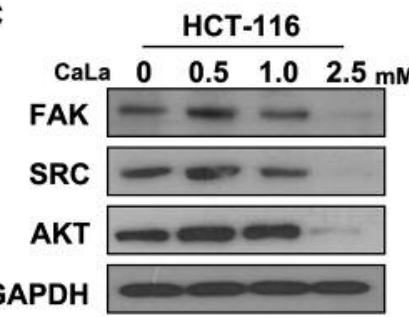

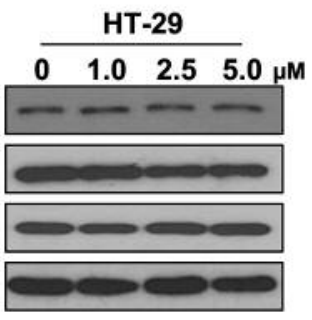
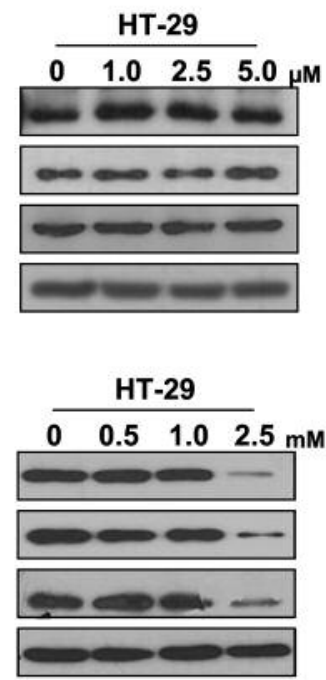
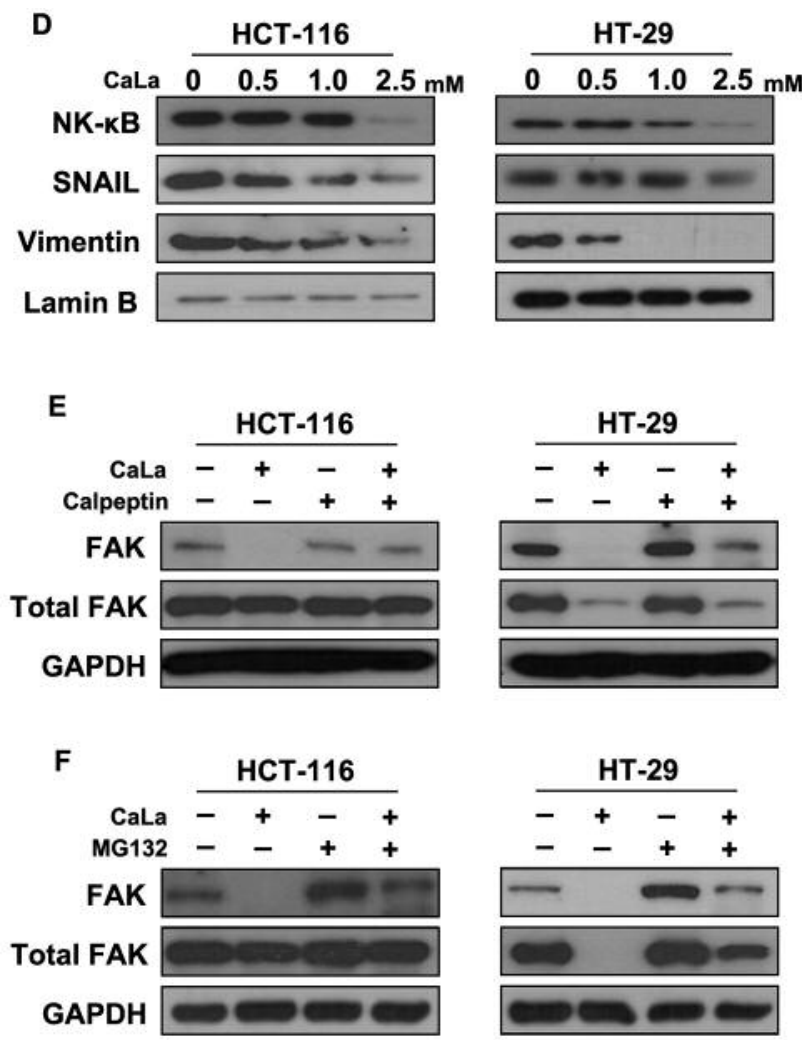

Figure 5. Comparison of the expression levels of focal adhesion kinase (FAK) signaling cascade elements using colorectal cancer (CRC) cells cultured on low-attachment plates to confirm the mechanism of anchorage-independent cell death. Cytosolic expression of FAK signaling molecules after treatment with different concentrations of 5-FU (A), and with lactate calcium salt (CaLa) $(C)$. Nuclear expression of nuclear factor-kappa $B$ $(N F-k B)$-dependent epithelial-mesenchymal transition markers after treatment with different concentrations of 5-FU (B) or CaLa $(D)$. E: Verification that the effect of calcium on FAK expression is mediated by calpain using calpeptin, a potent calpain inhibitor. F: Verification that calcium supplementation causes proteasomal degradation of FAK using Z-Leu-Leu-Leu-al (MG132), a potent proteasome inhibitor.

5-FU only slightly reduced the invasion rate of HCT-116 cells $(p<0.05)$ (Figure 8B).

We also assessed the mobility of CRC cells through wound-healing assays. In line with the previous results, 5-FU failed to inhibit cell motility in the metastatic environment. Inhibition of cell motility was however confirmed for consistent calcium supplementation via CaLa, and the best effect in inhibiting cell motility was through the combination treatment (Figure 8E).

\section{Discussion}

In this study, we investigated the enhanced anti-metastatic effect of 5-FU on CRC cells combined with continuous calcium supplementation. The results demonstrated that calcium-mediated FAK proteolysis is involved in inhibition of EMT signaling, leading to a significant suppression of CRC cell invasion and motility.
5-FU is an anti-metabolite that was developed as a potential antitumor drug (16). In cancer cells, 5-FU blocks access of deoxyuridine monophosphate to the nucleotidebinding site of thymidylate synthetase, inhibiting the synthesis of deoxythymidine monophosphate. This results in deoxynucleotide pool imbalances and an increased level of deoxyuridine triphosphate, both of which are factors leading to DNA damage (4).

Whereas 5-FU was able to exert its antitumor effect on anchored CRC cells, unanchored CRC cells tended to be resistant to 5-FU. Moreover, 5-FU failed to suppress the viability of CRC cells expressing EMT markers. This should come as no surprise; cultured cancer cells expressing such markers emulate in vivo EMT, and resistance to chemotherapeutic agents is an EMT-like characteristic (17).

However, a high dose of 5-FU (5 $\mu \mathrm{M})$ managed to increase cell death by anoikis. This can be attributed to a number of unanchored CRC cells still exhibiting features of anchorage- 
A

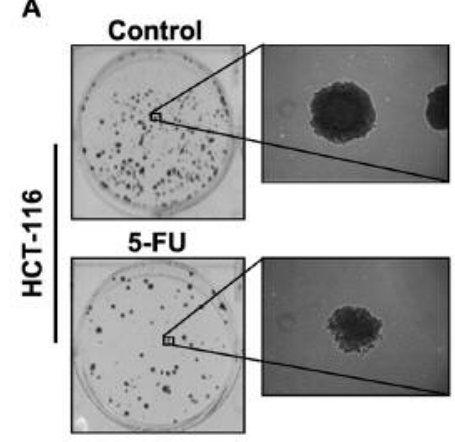

C

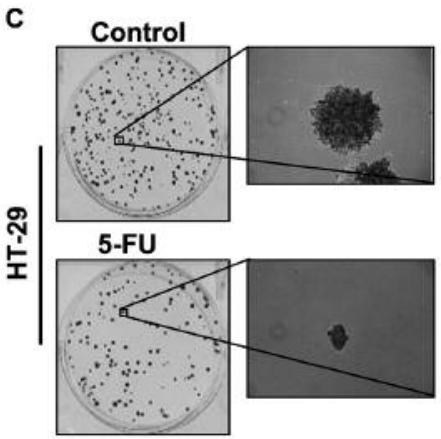

CaLa

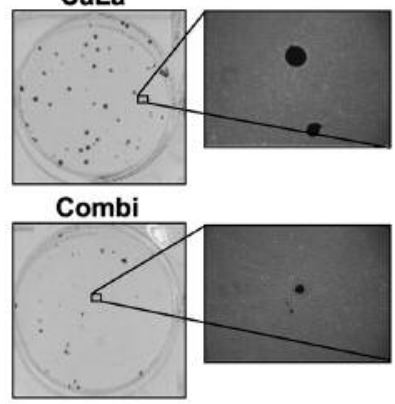

CaLa

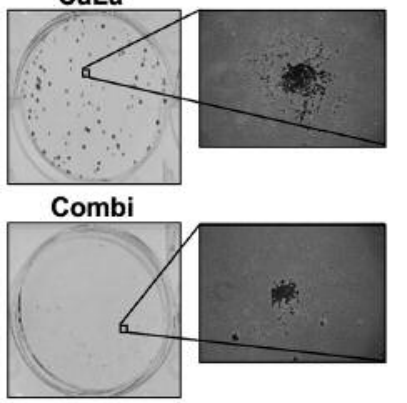

B

HCT-116

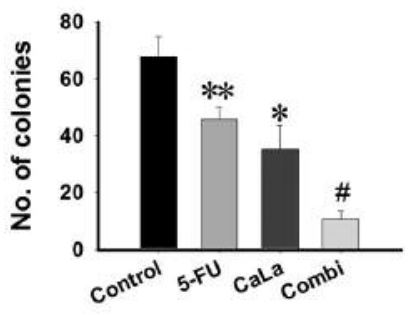

D

HT-29

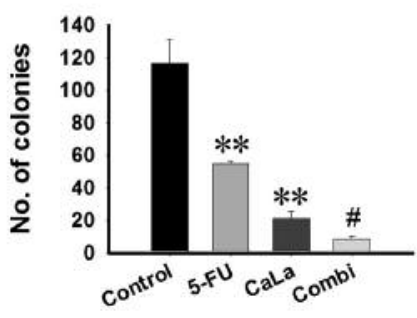

E

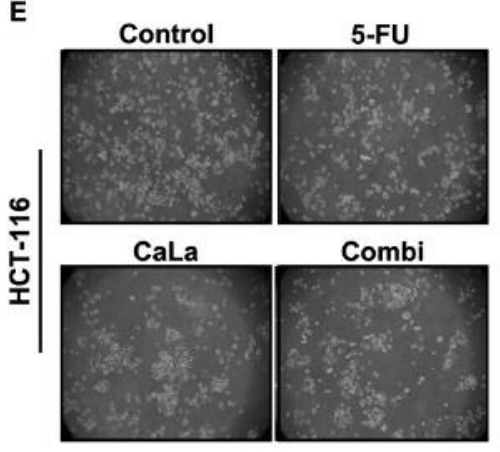

G

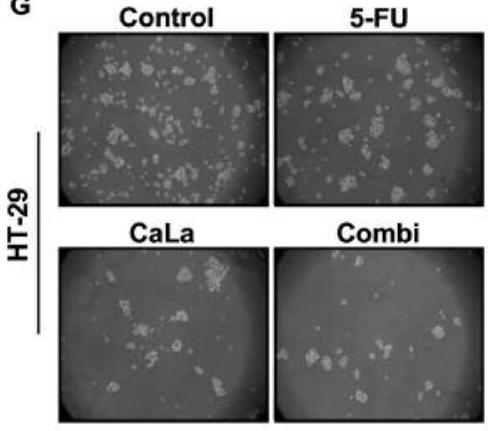

F

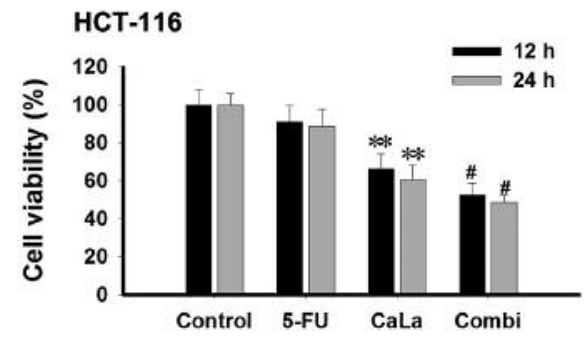

H

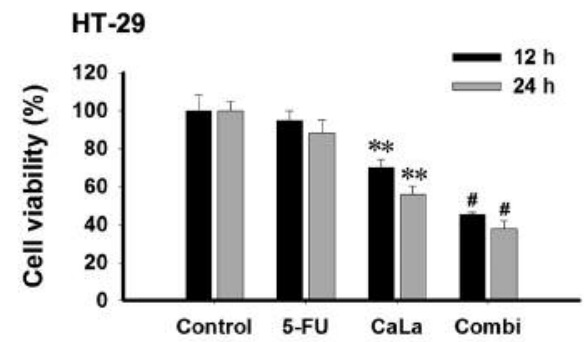

Figure 6. The effect of combination treatment on anchored and unanchored colorectal cancer (CRC) cell viability. Representative images (A, C) and quantitative analysis $(B, D)$ of HCT-116 $(A, B)$ and HT-29 $(C, D)$ colonies after single and combination treatment of 2.5 $\mu M$ 5-flourouracil $(5-F U)$ and $2.5 \mathrm{mM}$ lactate calcium salt $(C a L a)$. Representative images $(E, G)$ and quantitative analysis $(F, H)$ of HCT-116 $(E, F)$ and HT-29 $(G, H)$ cells cultured on low-attachment plates after single and combination treatment with $2.5 \mu M$ 5-FU and $2.5 \mathrm{mM}$ CaLa. All experiments were carried out in five replications per group. Results are means $\pm S D ;{ }^{*} p<0.05$ and ${ }^{* *} p<0.001$ vs. Control; ${ }^{*} p<0.001$ vs. Control, 5 -FU and CaLa groups. 
A

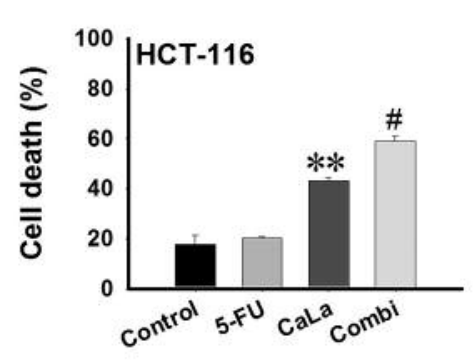

C

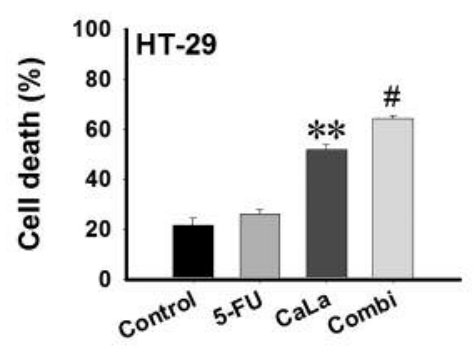

E

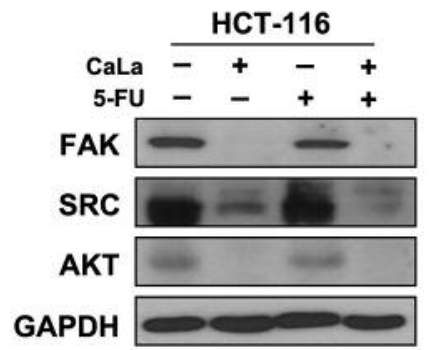

B
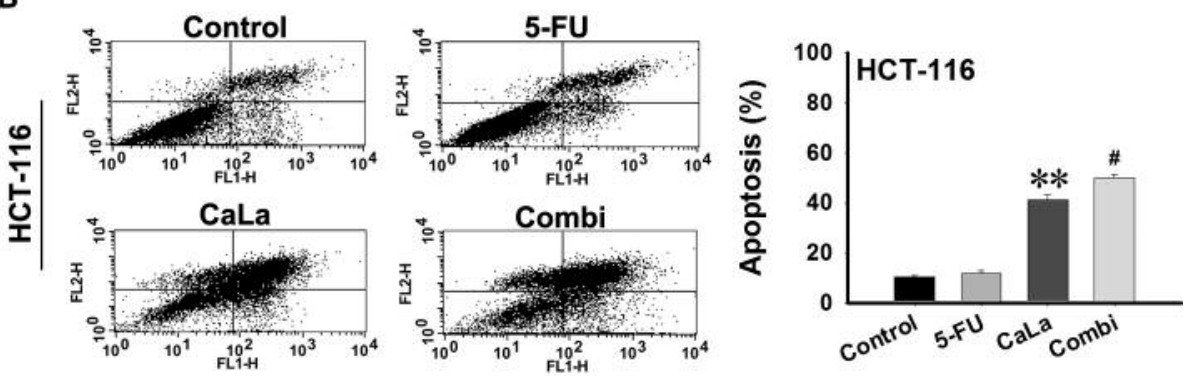

D
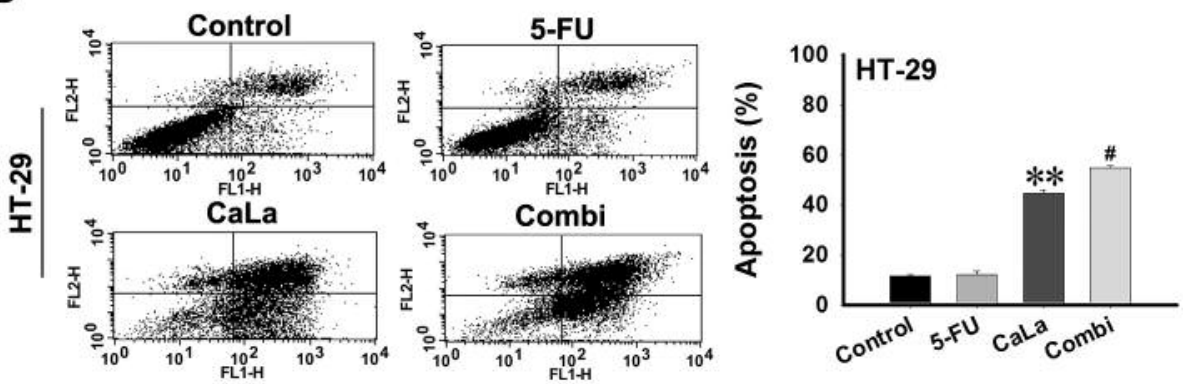

$\mathbf{F}$

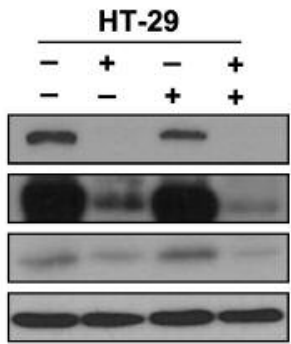

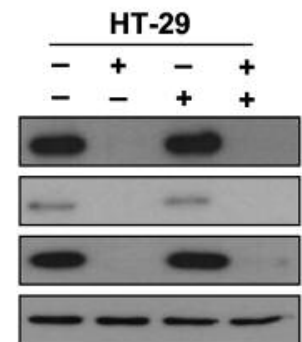

Figure 7. Determination of the combination treatment effect on anoikis using cultured colorectal cancer (CRC) cells cultured on low-attachment plates. Rates of cell death after re-seeding the unanchored HCT-116 (A) and HT-29 (C) cells on normal plates after single and combination treatment with $2.5 \mu \mathrm{M}$ 5-flourouracil (5-FU) and $2.5 \mathrm{mM}$ lactate calcium salt (CaLa). Quantitative analysis of late apoptosis in HCT-116 (B) and HT-29 (D) cells via fluorescence-activated cell sorting after annexin $V$ staining. E: Cytosolic expression of focal adhesion kinase (FAK) signaling molecules $(E)$ and nuclear expression of nuclear factor-kappa $B(N F-k B)$-dependent epithelial-mesenchymal transition markers $(F)$ after single and combination treatment with $2.5 \mu \mathrm{M} 5-F U$ and $2.5 \mathrm{mM}$ CaLa. Experiments were carried out in five replications per group. Results are means $\pm S D$; ${ }^{* *} p<0.001$ vs. Control; ${ }^{\# p} p 0.001$ vs. Control, 5-FU and CaLa groups. SRC: SRC proto-oncogene, non-receptor tyrosine kinase, AKT: AKT serinelthreonine kinase 1, snail family transcriptional repressor 1 (SNAIL), GAPDH: glyceraldehyde 3-phosphate dehydrogenase.

dependent cells. The FACS analysis revealed that none of the selected concentrations of 5-FU had a significant effect on anoikis-induced late apoptosis, compared to untreated controls. Taking these results into account, we decided to use a 5-FU concentration of $2.5 \mu \mathrm{M}$, i.e. half of the maximum tested dose, in the experiments investigating the suppressive effect of 5-FU combined with calcium supplementation. The fact that calcium supplementation managed to enhance the antitumor effect of 5-FU indicates that the combined treatment may represent a means of allowing the required therapeutic doses of 5-FU to be reduced (18).
The FAK signal cascade has been associated with cancer cell progression (11). FAK is involved in SRC-mediated phosphorylation, which is necessary for activation of proliferation signals, such as RAS (19). As a result, FAK regulates many growth factor signaling pathways that are important for the survival of human cancer cells (19). Additionally, complexes of FAK with SRC and phosphatidylinositol 3-kinase (PI3K) are well known differential regulators of cell migration (20). Mesenchymalderived stem cells are known to participate in cancer progression to the metastatic stage, as they play important 
A

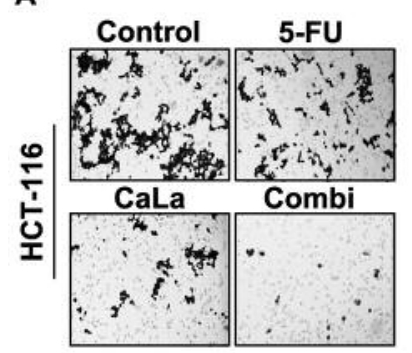

C

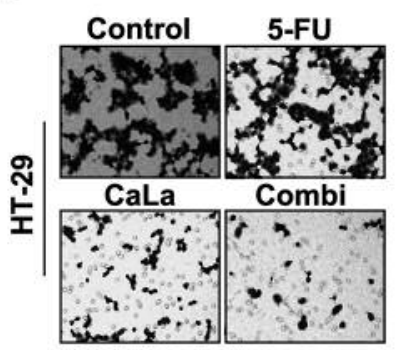

B

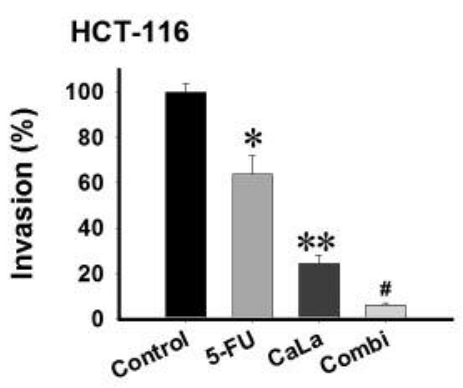

D

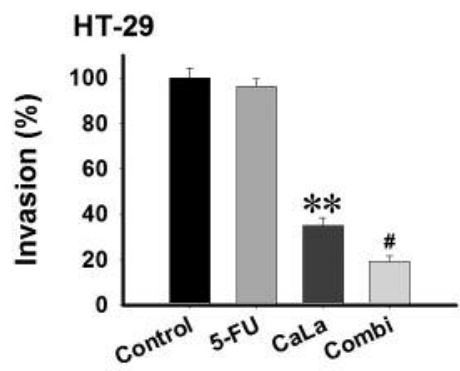

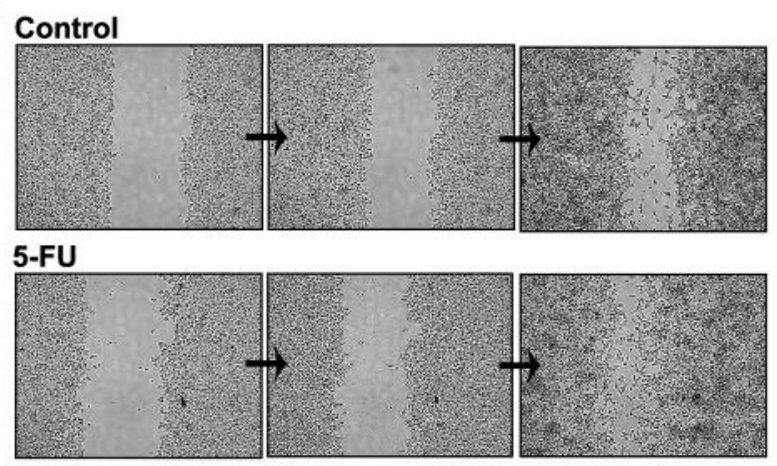

CaLa

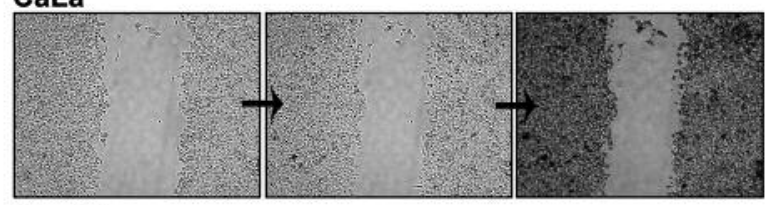

Combi

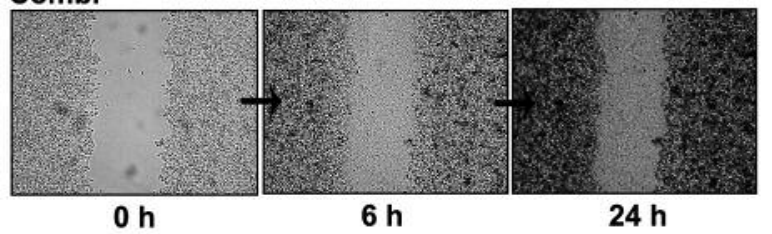

Figure 8. Confirmation of the enhanced anti-metastatic effect of the combination treatment on colorectal cancer (CRC) cells. Representative images $(A, C)$ and quantitative analysis $(B, D)$ demonstrating the suppression of $H C T-116(A, B)$ and HT-29 $(C, D)$ invasiveness by treatment with $2.5 \mu M$ 5-flourouracil (5-FU) and $2.5 \mathrm{mM}$ lactate calcium salt ( $\mathrm{CaLa}$ ). E: Chronological images for HCT-116 migration in wound-healing assay following single and combination treatment. Experiments were carried out in five replications per group (except in E). Results are means $\pm S D ; * p<0.05 v s$. Control; $* * p<0.001$ vs. Control and 5-FU; \#p<0.001 vs. Control, 5-FU and CaLa groups.

roles in cancer cell invasion and migration (21). PI3K and AKT, which are parts of the FAK signaling cascade, activate the expression of NF-KB, which constitutes a step of the metastatic process. NF-kB is translocated to the nucleus and up-regulates the expression of EMT markers, such as vimentin and SNAI1 $(19,20)$.

The present study demonstrated that calcium influx causes a calpain-mediated increase in FAK proteolysis, which is accompanied by a reduction in the levels of proteins participating in the FAK signaling cascade and EMT markers. Treatment with the specific proteasome inhibitor, MG132, or the calpain inhibitor, calpeptin, resulted in the recovery of FAK expression, confirming that the decrease in FAK level was indeed a result of calpain-mediated proteasomal degradation. The methods utilized for verifying the effects of calcium supplementation on protein degradation were devised according to previously published theories $(22,23)$. Our results demonstrate that treatment with a combination of calcium supplementation and 5-FU exerts an enhanced antitumor effect; calcium supplementation suppressed the metastatic and EMT features of CRC cells via
FAK degradation, significantly increasing the effectiveness of 5-FU against anchorage-independent CRC cells.

In this study, CaLa was used as a source of calcium supply. However, as the intracellular calcium concentration quickly (480 sec) plateaued, CaLa was continuously administered during the course of each experiment. Despite the existence of numerous reports on the subject, controversy still exists regarding the effectiveness of calcium supplementation in CRC prevention (24). Thus, further research work including cells derived from a variety of patients with CRC is required to confirm the antitumor effect of calcium supplementation.

In conclusion, FAK proteolysis induced by the continuous supply of calcium was able to significantly reduce expression of EMT markers and inhibit the metastatic features of CRC cells. We also confirmed that the combination of 5-FU and calcium supplementation can significantly enhance the antimetastatic effect of 5-FU on CRC cells, even when a lower dose of 5-FU is used. Inducing an immediate increase in anti-metastatic effect through simple calcium intake may be difficult in a clinical setting. However, if a steady supply is 
provided through an appropriate method, calcium may be able to increase the effectiveness of existing antitumor agents, such as 5-FU.

\section{Conflicts of Interests}

The Authors declare that there are no conflicts of interest in regard to this study.

\section{References}

1 Wheat CL, Clark-Snustad K, Devine B, Grembowski D, Thornton TA and Ko CW: Worldwide incidence of colorectal cancer, leukemia, and lymphoma in inflammatory bowel disease: An updated systematic review and meta-analysis. Gastroenterol Res Pract 2016: 1632439, 2016.

2 Torre LA, Bray F, Siegel RL, Ferlay J, Lortet-Tieulent J and Jemal A: Global cancer statistics, 2012. CA Cancer J Clin 65(2): 87-108, 2015.

3 Fakih MG: Metastatic colorectal cancer: Current state and future directions. J Clin Oncol 33(16): 1809-1824, 2015.

4 Longley DB, Harkin DP and Johnston PG: 5-fluorouracil: Mechanisms of action and clinical strategies. Nat Rev Cancer 3(5): 330-338, 2003.

5 Pohl A, Zhang W, Ning Y, Manegold PC, Lurje G and Lenz HJ: Targeting metastatic colorectal cancer in 2008: A long way from 5-FU. Oncology 22(4): 456-462; discussion 462-453, 467-458, 474 passim, 2008.

6 Tol J, Koopman M, Cats A, Rodenburg CJ, Creemers GJ, Schrama JG, Erdkamp FL, Vos AH, van Groeningen CJ, Sinnige HA, Richel DJ, Voest EE, Dijkstra JR, Vink-Borger ME, Antonini NF, Mol L, van Krieken JH, Dalesio O and Punt CJ: Chemotherapy, bevacizumab, and cetuximab in metastatic colorectal cancer. N Engl J Med 360(6): 563-572, 2009.

7 Hwang JJ: Irinotecan and 5-fu/leucovorin in metastatic colorectal cancer: Balancing efficacy, toxicity, and logistics. Oncology 18(14 Suppl 14): 26-34, 2004.

8 Chibaudel B, Tournigand C, Bonnetain F, Richa H, Benetkiewicz $\mathrm{M}$, Andre $\mathrm{T}$ and de Gramont A: Therapeutic strategy in unresectable metastatic colorectal cancer: An updated review. Ther Adv Med Oncol 7(3): 153-169, 2015.

9 McLean GW, Carragher NO, Avizienyte E, Evans J, Brunton VG and Frame MC: The role of focal-adhesion kinase in cancer - a new therapeutic opportunity. Nat Rev Cancer 5(7): 505-515, 2005.

10 Frisch SM, Schaller M and Cieply B: Mechanisms that link the oncogenic epithelial-mesenchymal transition to suppression of anoikis. J Cell Sci 126(Pt 1): 21-29, 2013.

11 Sulzmaier FJ, Jean C and Schlaepfer DD: FAK in cancer: Mechanistic findings and clinical applications. Nat Rev Cancer 14(9): 598-610, 2014.

12 Ono Y and Sorimachi H: Calpains: An elaborate proteolytic system. Biochim Biophys Acta 1824(1): 224-236, 2012.

13 Mitra SK, Hanson DA and Schlaepfer DD: Focal adhesion kinase: In command and control of cell motility. Nat Rev Mol Cell Biol 6(1): 56-68, 2005.
14 Schafer AL and Shoback DM: Hypocalcemia: Diagnosis and treatment. In: Endotext. De Groot LJ, Beck-Peccoz P, Chrousos G, Dungan K, Grossman A, Hershman JM, Koch C, McLachlan R, New M, Rebar R, Singer F, Vinik A and Weickert MO (eds.). South Dartmouth (MA), 2000.

15 Sundaramoorthy P, Sim JJ, Jang YS, Mishra SK, Jeong KY, Mander P, Chul OB, Shim WS, Oh SH, Nam KY and Kim HM: Modulation of intracellular calcium levels by calcium lactate affects colon cancer cell motility through calcium-dependent calpain. PLoS One 10(1): e0116984, 2015.

16 Heidelberger C, Chaudhuri NK, Danneberg P, Mooren D, Griesbach L, Duschinsky R, Schnitzer RJ, Pleven E and Scheiner J: Fluorinated pyrimidines, a new class of tumourinhibitory compounds. Nature 179(4561): 663-666, 1957.

17 Abdullah LN and Chow EK: Mechanisms of chemoresistance in cancer stem cells. Clin Transl Med 2(1): 3, 2013.

18 de Forni M, Malet-Martino MC, Jaillais P, Shubinski RE, Bachaud JM, Lemaire L, Canal P, Chevreau C, Carrie D, Soulie $\mathrm{P}$ et al: Cardiotoxicity of high-dose continuous infusion fluorouracil: A prospective clinical study. J Clin Oncol 10(11): 1795-1801, 1992.

19 Bouchard V, Demers MJ, Thibodeau S, Laquerre V, Fujita N, Tsuruo T, Beaulieu JF, Gauthier R, Vezina A, Villeneuve L and Vachon PH: Fak/src signaling in human intestinal epithelial cell survival and anoikis: Differentiation state-specific uncoupling with the PI3-K/AKT-1 and MEK/ERK pathways. J Cell Physiol 212(3): 717-728, 2007.

20 Reiske HR, Kao SC, Cary LA, Guan JL, Lai JF and Chen HC: Requirement of phosphatidylinositol 3-kinase in focal adhesion kinase-promoted cell migration. J Biol Chem 274(18): 1236112366, 1999.

21 Chang AI, Schwertschkow AH, Nolta JA and Wu J: Involvement of mesenchymal stem cells in cancer progression and metastases. Curr Cancer Drug Targets 15(2): 88-98, 2015.

22 Chan KT, Bennin DA and Huttenlocher A: Regulation of adhesion dynamics by calpain-mediated proteolysis of focal adhesion kinase (FAK). J Biol Chem 285(15): 11418-11426, 2010.

23 Kisselev AF and Goldberg AL: Proteasome inhibitors: From research tools to drug candidates. Chem Biol 8(8): 739-758, 2001.

24 Wactawski-Wende J, Kotchen JM, Anderson GL, Assaf AR, Brunner RL, O'Sullivan MJ, Margolis KL, Ockene JK, Phillips L, Pottern L, Prentice RL, Robbins J, Rohan TE, Sarto GE, Sharma S, Stefanick ML, Van Horn L, Wallace RB, Whitlock E, Bassford T, Beresford SA, Black HR, Bonds DE, Brzyski RG, Caan B, Chlebowski RT, Cochrane B, Garland C, Gass M, Hays J, Heiss G, Hendrix SL, Howard BV, Hsia J, Hubbell FA, Jackson RD, Johnson KC, Judd H, Kooperberg CL, Kuller LH, LaCroix AZ, Lane DS, Langer RD, Lasser NL, Lewis CE, Limacher MC, Manson JE and Women's Health Initiative I: Calcium plus vitamin D supplementation and the risk of colorectal cancer. N Engl J Med 354(7): 684-696, 2006.

Received October 20, 2016

Revised November 16, 2016 Accepted November 29, 2016 